\title{
Migração internacional e novas espacialidades no Litoral Norte de São Paulo
}

\author{
Guilherme Pereira Botacini ${ }^{1}$ \\ Rosana Baeninger ${ }^{2}$
}

\section{Introdução}

O início do século 21, de acordo com Sassen (1998), amplia o cenário da globalização para distintas localidades do mundo, expressando a expansão de uma economia que busca acrescentar, cada vez mais, novos espaços à dinâmica do capital transnacional. Nesse contexto, localidades que anteriormente apresentavam características vinculadas tanto ao desenho do território, como o caso do Litoral, quanto às suas raízes históricas passam a compor também a dinâmica global. De fato, Baeninger (2015:15) analisa que

“à medida que as localidades se inserem na lógica das atividades transnacionais, as migrações internas e internacionais tenderão a se intensificar, correspondendo à mesma velocidade da mobilidade do capital na contemporaneidade, com a consequente redefinição da migração nesses espaços”.

As transformações recentes nos processos migratórios neste espaço do Litoral Norte paulista revelam a concomitância da migração interna e internacional, em particular pelas atividades de extração do petróleo e do pólo logístico portuário. Este novo contexto local reflete a posição deste espaço portuário na atual divisão social do trabalho em São Paulo (GONÇALVES, 1998) e a configuração de novas dinâmicas socioespaciais e migratórias face à lógica de novos investimentos produtivos transnacionais. Nesse sentido, a partir da análise de dados do CNIg, podemos observar que a indústria do turismo marítimo também marca presença no litoral norte, trazendo consigo trabalhadores migrantes marítimos, em sua maioria filipinos. Os dados serão apresentados mais à frente.

As migrações internas no país assumem maior complexidade a partir das últimas décadas do século 20 (Cunha, 2011), em particular, pelas tendências, características e sentidos das migrações no Estado de São Paulo e suas diferentes regiões (BAENINGER, 2012). Nesse contexto, o século 21 traz importantes desafios para o entendimento dos novos processos socioespaciais em São Paulo,

1 Mestrando no Programa de Pós-Graduação em Demografia da Universidade Estadual de Campinas.E-mail de contato: guilhermepbotacini@gmail.com

2 Professora do Departamento de Demografia e do Núcleo de Estudos de População Elza Berquó da Universidade Estadual de Campinas. E-mail de contato: baeninger@ nepo.unicamp.br 
destacando a importância que as "vocações regionais" (HARVEY, 2003) tendem a apresentar na articulação entre processos locais e globais.

A contextualização e o entendimento do processo de reestruturação urbana atual remetem, por sua vez, às transformações recentes da economia em âmbito internacional e à nova divisão social do trabalho. Desse modo, o elemento central da reestruturação econômica está calcado sob as novas formas de flexibilização da produção e sob a transformação vigorosa nos serviços de coordenação financeira, permitindo flexibilizar a forma fordista de acumulação e a dinâmica espacial desse sistema (HARVEY, 1992).

\section{Desenvolvimento}

De acordo com Monié e Vidal (2006:975)

“a reorganização mundial dos espaços produtivos e o surgimento de dinâmicas comerciais específicas incluíram também um conjunto de mudanças na estrutura mundial dos portos: novos métodos de movimentação de cargas, equipamentos com sofisticação tecnológica, mão-de-obra especializada e agilidade”.

Esta dinâmica traz demandas e impactos na constituição da nova cidade portuária globalizada, resultando - como afirmam os autores - "em mudanças no sistema portuário mundial e nas cidades com portos" (MONIÉ e VIDAL, 2006:977). Trata-se, portanto, de considerar a cidade portuária e sua inserção nos processos produtivos mundiais, com a ampliação da cadeia produtiva e novos desafios e transformações locais.

Os autores indicam três tendências para os portos no Brasil, considerando o conjunto das transformações recentes tanto no sistema portuário do país quanto da estrutura mundial dos portos. A primeira se refere

“aos portos de Santos e Rio de Janeiro, por exemplo, consiste na modernização do porto da era industrial. Segundo essa lógica, o porto tradicional caro, engessado do ponto de vista operacional e institucional, negativamente impactante sobre meio ambiente deve ser modernizado por intermédio de investimentos nas infra-estruturas e equipamentos portuários e uma reengenharia institucional, quebrando os monopólios" (MONIÉ e VIDAL, 2006)

A segunda tendência, de acordo com os autores, refere-se à 
“construção de megaportos voltados para a concentração e a redistribuição dos fluxos do comércio internacional para portos marítimos ou hinterlands terrestres. Os portos de tipo hubs funcionam como instrumentos a serviço de multinacionais marítimas - os integradores globais e terrestres - que formam redes de circulação globais onde meganavios circulam em megarrotas marítimas e servem somente a megaportos estrategicamente localizados (...) os investimentos são consideráveis, as tecnologias de manuseio das cargas restringem a criação de empregos, as interações com o local de implantação são também limitadas, pois a função maior da plataforma portuária reside na sua capacidade de redistribuir imediatamente os fluxos que para ela convergem. Ou seja, o porto é um simples equipamento de transporte inserido numa rede global e a serviço da lógica exclusivamente global das multinacionais, que beneficia pouco o lugar onde ele se localiza. Por isso, o hub é sempre apresentado como enclave desterritorializado que não contribui para o desenvolvimento da região onde foi implantado" (MONIÉ e VIDAL, 2006)

A terceira tendência é indicada pelos autores considerando

"a transformação do porto em instrumento a serviço do desenvolvimento local elou regional por meio de uma aproximação do porto e da cidade. A chamada "cidade portuária" prioriza, com efeito, a agregação de valor aos fluxos de cargas que transitam pelos seus portos. Trata-se, nesse caso, de uma leitura diferenciada do processo de globalização que, além do crescimento das trocas comerciais internacionais, caracteriza-se por uma transformação do modo de produzir que implica a agregação de um número crescente de atividades terciárias ao núcleo material do bem (...). A combinação dessas características oferece, assim, oportunidades de desenvolvimento às cidades-portos que apostam na 'mercantilização' dos fluxos pelo estabelecimento de sinergias entre os recursos técnicos, oferecidos pelo porto e os serviços de transporte, e os recursos terciários oferecidos pelo tecido produtivo urbano” (MONIÉ e VIDAL, 2006:985).

Dentre essas classificações dos autores para os impactos e dinâmicas sociespaciais referentes ao Porto de São Sebastião, no Litoral Norte, no contexto da globalização dos portos, parece haver uma aproximação do porto e da cidade, portanto, situação próxima à terceira tendência apresentada por Monié e Vidal (2006).

De fato, na última década, o Litoral Norte paulista recebeu novos investimentos que o colocaram definitivamente no radar do setor energético e logístico do país (CARMO, 2012). Se antes a região, especialmente ancorada na figura do TEBAR (Terminal de São Sebastião; terminal 
privativo da Petrobrás) possuía alguma importância nos planos da estatal do petróleo e dos diversos capitais vinculados ao setor de petróleo e gás, atualmente - a despeito da atual crise política e financeira - houve a ampliação dos diversos negócios do setor: a construção da UTCGA (Estação de Tratamento de Gás Monteiro Lobato) em 2013, em Caraguatatuba, e a descoberta dos campos de exploração da camada Pré-Sal na costa do sudeste brasileiro. Nesse cenário, o Litoral Norte paulista se inseriu na estratégia de articulação global do capital transnacional com reflexos em sua dinâmica local.

A potencialidade do Porto de São Sebastião é de se notar por possuir a maior entrada de petróleo cru, diesel, gasolina e nafta do país (CARMO, 2012). Além disso, conta com os investimentos do setor de petróleo e gás na região, e, numa escala nacional e global - a partir da crescente entrada e expansão do capital transnacional no país - abriu caminho para uma nova onda de investimentos na malha logística da região: a duplicação da Rodovia dos Tamoios e sua concessão, já concluídas; a construção do contorno viário ligando São Sebastião (quase diretamente o porto) e Caraguatatuba; duplicação do trecho de serra da Rodovia dos Tamoios em Caraguatatuba e, a ampliação do próprio Porto de São Sebastião e os de projetos para aumento da hinterland portuária. Nesse sentido, a aproximação entre porto e cidade parece se evidenciar na região.

Mapa 1 - Localização das Cidades de Caraguatatuba e São Sebastião

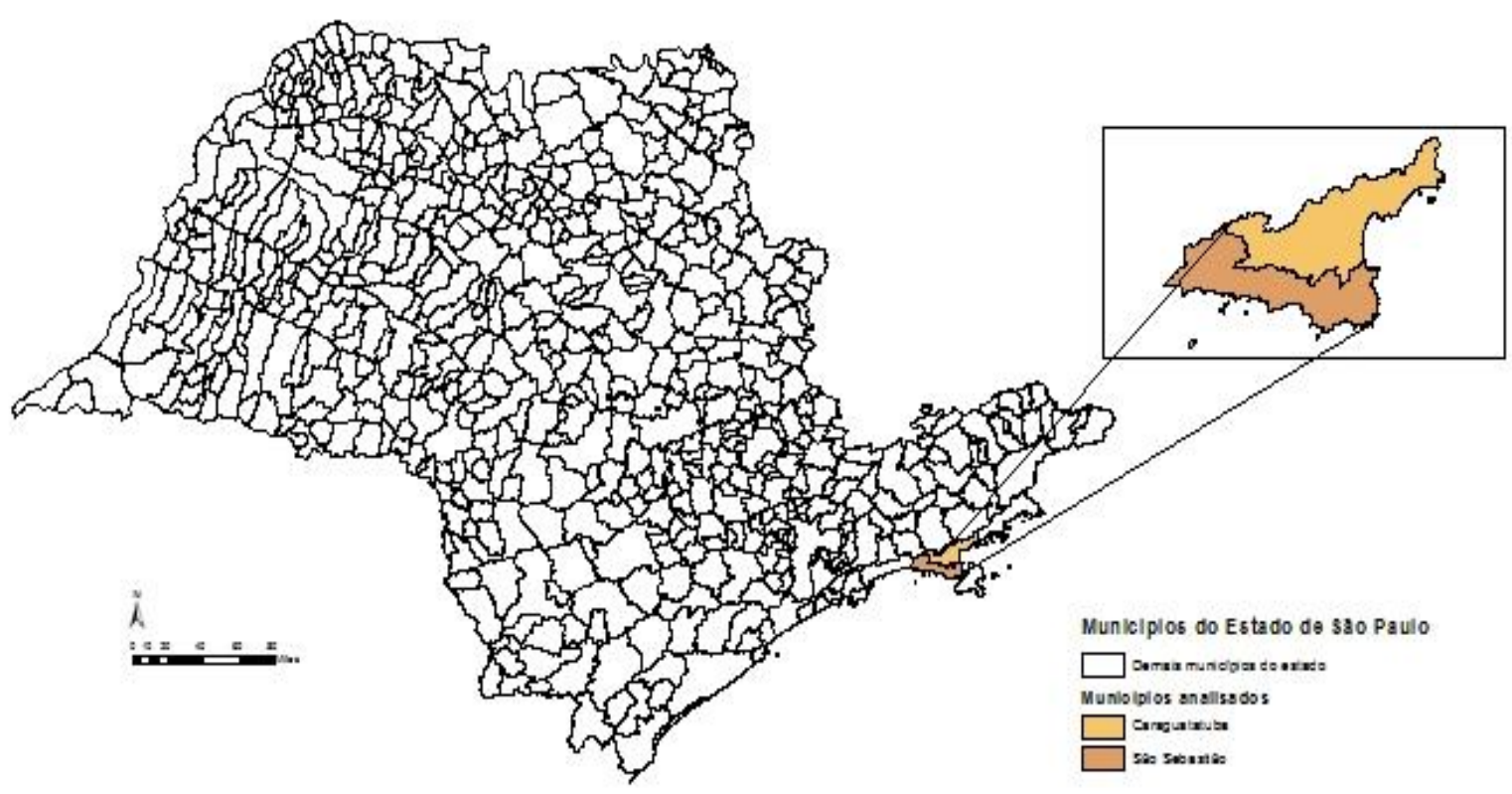

De "cidade caiçara", majoritariamente rural até a década de 1960 (SILVA, 1975 apud LUCHIARI, 1992), com atividades relacionadas à pesca e à agricultura e marcada pela cultura local caiçara, as cidades da região passaram a "cidades litorâneas" a partir dos anos 1970, entrando para o 
circuito turístico estadual com a construção do trecho da rodovia federal BR-101 que transpassa Ubatuba, Caraguatatuba e São Sebastião (LUCHIARI, 1992). Apesar da rápida urbanização e do grande contingente migratório que transformou a região, entre os anos 1970 e 2000, a sazonalidade da população de veraneio (CARMO, 2012 e LUCHIARI 1992) reafirmava as características de cidade litorânea e de turismo balneário.

O século XXI, contexto que traz a modernização portuária e os investimentos regionais que modificam as feições da cidade, embora persista a população flutuante para o lazer, aponta novas lógicas, mercados e "vocações" para a região. No novo contexto de "cidade portuária", uma característica marcante da região nos anos recentes é a presença de imigrantes internacionais, revelando sua inserção em âmbito global.

De fato, dentre as transformações socioespaciais, a cidade portuária e sua região apresenta uma inédita imigração internacional a partir de 2010, identificada a partir da análise da base de dados do Sistema Nacional de Cadastro e Registro de Estrangeiros da Polícia Federal (SINCRE$\mathrm{PF})^{3}$. A base consultada possui registros de 2000 a 2015, e suas informações apresentam idade, sexo, país e cidade de origem, ano de entrada no Brasil, profissão, tipo do visto concedido, dentre outras. Alguns pontos específicos merecem ser destacados para caracterizar essa presença na "cidade portuária".

Primeiramente, o volume diferencial de imigrantes internacionais registrados em Caraguatatuba e em São Sebastião: enquanto na primeira, cidade mais populosa do litoral norte, contamos 285 imigrantes internacionais, sendo 177 vistos permanentes e 108 provisórios ou temporários, em São Sebastião, cidade portuária, contamos 4.415 estrangeiros, sendo 151 vistos permanentes e 4264 vistos provisórios ou temporários. Essa presença imigrante internacional em São Sebastião é reveladora de sua nova posição como cidade portuária e seus vínculos globais.

Considerando a estrutura etária e por sexo dos imigrantes internacionais, nas duas cidades (Gráfico 1 e 2), nota-se que, enquanto Caraguatatuba aponta para uma diversificação maior dos imigrantes internacionais por idade, inclusive com pessoas entre 0 e 14 anos e acima de 60 anos, São Sebastião apresenta uma população de imigrantes internacionais formada quase completamente por homens entre 30 e 44 anos, o que expressa o mercado global de trabalhadores imigrantes internacionais na cidade portuária.

\footnotetext{
${ }^{3}$ Agradecemos a parceria com o Professor Duval Fernandes da PUC/Minas na disponibilização e análises dessas informações.
} 


\section{Gráfico 1}

Estrutura Etária de Imigrantes Internacionais com registro ativo

Caraguatatuba, 2000-2015

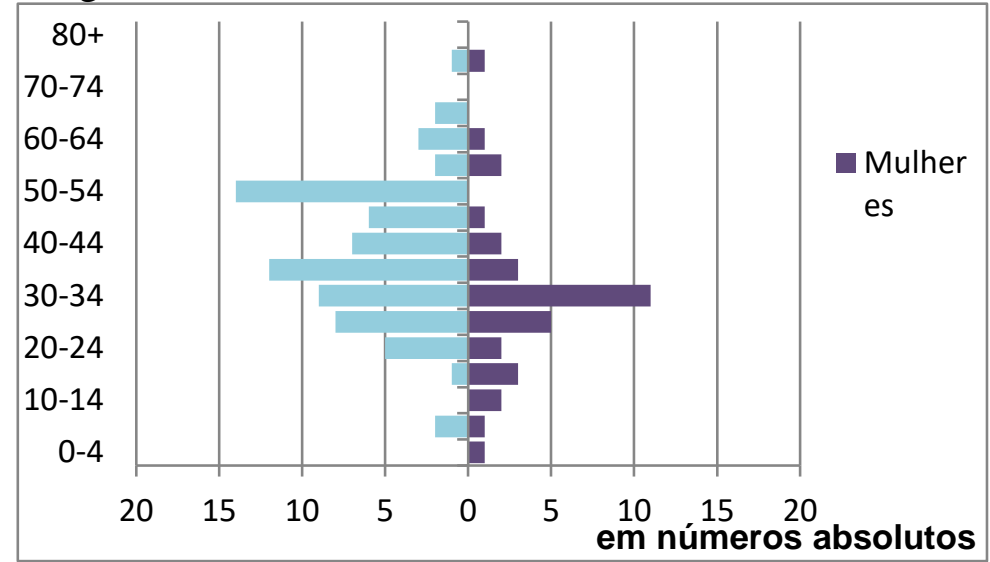

Fonte: Sistema Nacional de Cadastro e Registros de Estrangeiros. Polícia Federal- Ministério da Justiça/Projeto MT Brasil - ICMPD/PUC Minas. Tabulações Observatório das Migrações em São Paulo (Fapesp-NEPO/UNICAMP).

Gráfico 2

Estrutura Etária de Imigrantes Internacionais com registro ativo

São Sebastião, 2000-2015

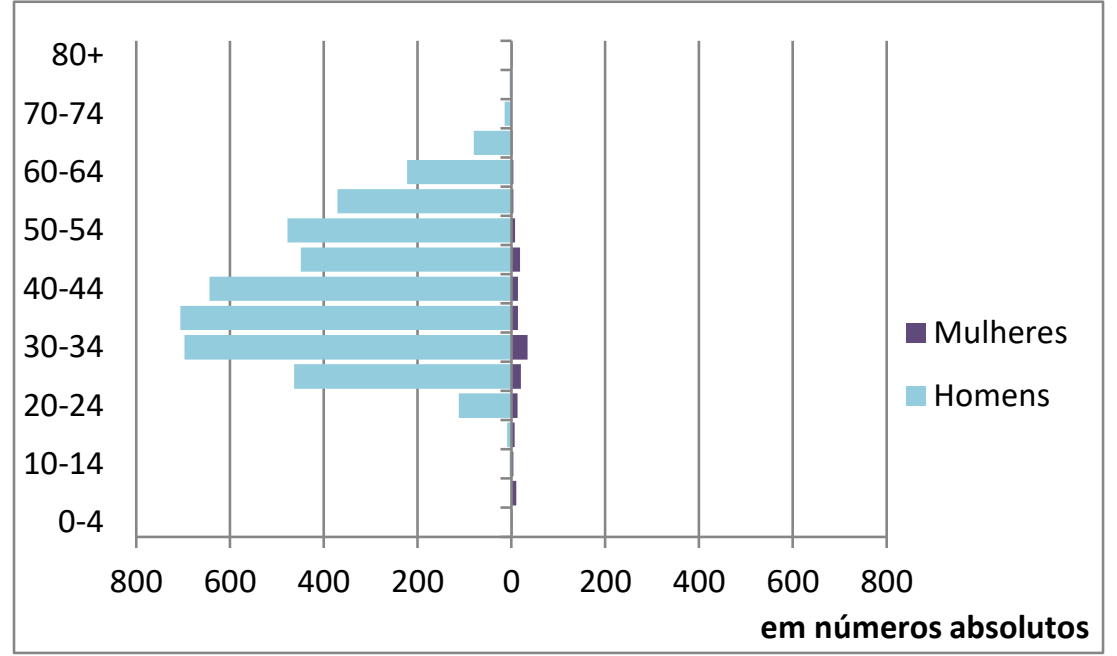

Fonte: Sistema Nacional de Cadastro e Registros de Estrangeiros. Polícia Federal-Ministério da Justiça/Projeto MT Brasil - ICMPD/PUC Minas. Tabulações Observatório das Migrações em São Paulo (Fapesp-NEPO/UNICAMP).

A estrutura de ocupações dos imigrantes internacionais também apresenta especificidades. 
Tabela 1

Profissões predominantes de Imigrantes Internacionais com registro ativo Caraguatatuba e São Sebastião, 2000 - 2015

\begin{tabular}{|c|c|c|c|}
\hline \multicolumn{3}{|c|}{ Profissões Predominantes } \\
\hline \multicolumn{2}{|c|}{ Caraguatatuba } & 20 & São Sebastião \\
\hline Aposentado & 17 & Cozinheiroto & 25 \\
Arquiteto & Estudante & 13 \\
Diretor, Gerente ou Proprietário & 24 & Oficial & 4103 \\
Estudante & 39 & Ocupações não-classificadas & 46 \\
Mecânico & 12 & Prendas Domésticas & 14 \\
Ocupações não-classificadas & 13 & Professor & 13 \\
Prendas Domésticas & 19 & Vendedor & 11 \\
Professor & 16 & \\
Profissional Liberal & 18 & & \\
Vendedor & 17 & Total & $\mathbf{4 4 1 5}$ \\
Total & $\mathbf{2 8 5}$ &
\end{tabular}

Fonte: Sistema Nacional de Cadastro e Registros de Estrangeiros. Polícia Federal-Ministério da Justiça/Projeto MT Brasil - ICMPD/PUC Minas. Tabulações Observatório das Migrações em São Paulo (Fapesp-NEPO/UNICAMP).

Em Caraguatatuba não há predomínio de uma profissão, mas vemos que há estudantes, profissionais liberais, professores, aposentados, dentre outras profissões, sem que nenhuma se destaque. Por outro lado, isso não ocorre em São Sebastião, onde a profissão mais registrada no SINCRE-PF é a de "Oficial", relacionado a trabalhadores marítimos. Dos 4.415 estrangeiros registrados, 2.861 estão sob o Amparo Legal 166, que versa sobre o visto temporário concedido a trabalhadores estrangeiros a bordo de embarcações ou plataformas estrangeiras; também estão presentes estudantes, arquitetos e cozinheiros de várias nacionalidades.

As nacionalidades predominantes em cada um dos municípios também possibilitam alguns comentários a respeito da inserção da região nas lógicas globais. A tabela abaixo traz as nacionalidades predominantes nos dois municípios. 
Tabela 2

Nacionalidades predominantes dos Imigrantes Internacionais com registro ativo

Caraguatatuba e São Sebastião, 2000 - 2015.

\begin{tabular}{|c|c|c|c|c|c|}
\hline \multicolumn{6}{|c|}{ Nacionalidades Predominantes } \\
\hline Caraguatatuba & & $\begin{array}{c}\text { Proporção } \\
\text { do Total de } \\
\text { Estrangeiro } \\
\mathrm{s} \\
\end{array}$ & \multicolumn{2}{|l|}{ São Sebastião } & $\begin{array}{c}\text { Proporção } \\
\text { do Total de } \\
\text { Estrangeiro } \\
\text { s } \\
\end{array}$ \\
\hline Argentina & 31 & & Argentina & 73 & \\
\hline Bolívia & 9 & & Chile & 25 & \\
\hline Chile & 7 & & Colômbia & 14 & \\
\hline Colômbia & 16 & & México & 10 & \\
\hline México & 11 & & Peru & 32 & \\
\hline Paraguai & 8 & & El Salvador & 49 & \\
\hline Peru & 10 & & Latinoamericanos & 226 & $5,12 \%$ \\
\hline Uruguai & $\begin{array}{r}7 \\
\mathbf{1 0}\end{array}$ & & Croácia & 91 & \\
\hline Latinoamericanos & 4 & $36,75 \%$ & Geórgia & 44 & \\
\hline EUA & 24 & & Grécia & 462 & \\
\hline Itália & 17 & & Letônia & 49 & \\
\hline Romênia & 5 & & Noruega & 113 & \\
\hline Inglaterra & 8 & & Polônia & 436 & \\
\hline \multirow[t]{2}{*}{ Portugal } & 29 & & Romênia & 73 & \\
\hline & 12 & & & & \\
\hline EUA/Europa/Oceania & 1 & $42,76 \%$ & Rússia & 256 & \\
\hline China & 31 & & Ucrânia & 81 & \\
\hline Japão & 6 & & União Soviética & 38 & \\
\hline \multicolumn{3}{|l|}{ Ásia/África/Oriente } & & 201 & \\
\hline Médio & 58 & $20,49 \%$ & EUA/Europa/Oceania & 2 & $\mathbf{4 5 , 5 7 \%}$ \\
\hline & & & & 173 & \\
\hline & & & Filipinas & 4 & \\
\hline & & & Índia & 289 & \\
\hline & & & China & 48 & \\
\hline & & & Ásia/África/Oriente & 217 & \\
\hline & & & Médio & 4 & $49,24 \%$ \\
\hline
\end{tabular}

Fonte: Sistema Nacional de Cadastro e Registros de Estrangeiros. Polícia Federal-Ministério da Justiça/Projeto MT Brasil - ICMPD/PUC Minas. Tabulações Observatório das Migrações em São Paulo (Fapesp-NEPO/UNICAMP).

É possível notar que a proporção de latinoamericanos em Caraguatatuba é muito mais elevada que em São Sebastião: são imigrantes de várias nacionalidades, em várias profissões, sem predominância de uma característica específica. Já em São Sebastião, o panorama é diferente. Não bastasse a ocupação "Oficial” ser absolutamente majoritária, uma nacionalidade em específico se destaca das demais: os Filipinos. Em sua maioria casados, quase todos homens, são, também, todos trabalhadores marítimos, registrados como “Oficial”. Sendo responsáveis por quase $40 \%$ do total de estrangeiros registrado pelo SINCRE-PF no município, essa força de trabalho é característica do 
trabalho nas indústrias de petróleo e derivados e do turismo marítimo. As autorizações de trabalho para trabalhadores estrangeiros em embarcações ou plataformas estrangeiras no Brasil dobraram entre 2006 e 2013 (ALVES, 2015), e a força de trabalha filipina (assim como de outros países asiáticos), foi responsável por boa parte desse aumento. Por constituírem uma força de trabalho barata, flexível e, de alguma maneira, invisível, os filipinos são arregimentados por agências de emprego, contratados por empresas (muitas vezes terceirizadas) com a anuência e parceria do Estado. Também faz parte dessa força de trabalho marítima global trabalhadores do Leste Europeu e de países da antiga União Soviética (ZANIN apud ALVES, 2015).

$\mathrm{Na}$ Resolução Normativa $\mathrm{n}^{\circ} 72$, do Conselho Nacional de Imigração, são exigidos os documentos no caso de contratação de "prestação de serviços e de risco": "cópia do contrato de afretamento celebrado com empresa brasileira ou do contrato de prestação de serviços, ou do contrato de risco, celebrado com empresa brasileira, ou da Portaria de Concessão editada pela Agência Nacional do Petróleo; "4 . Assim, o setor de petróleo e gás - com Estado bastante presente enquanto órgão regulatório, na figura da ANP - se mostra extremamente atuante na contratação dessa força de trabalho imigrante internacional, com Resolução Normativa específica para definir os parâmetros legais para este tipo de concessão de visto ao trabalhador imigrante internacional.

No caso da região estudada, de fato, a descoberta dos campos de petróleo e gás natural exploráveis da camada pré-sal contribuíram para o aumento dos investimentos no setor e em setores adjuntos, como a engenharia naval e a logística. A UTGCA (Estação de Tratamento de Gás Monteiro Lobato) em Caraguatatuba - construída em 2011 e ampliada em 2014 - é o primeiro ponto em terra para escoamento do gás natural retirado da Bacia de Santos, na camada pré-sal, nos campos de Tambaú, Uruguá e Lula.

O campo de Lula é um dos maiores campos da camada pré-sal, com 25\% de concessão para o BG Group, foi comprado pela Shell, em 2016, e 10\% pela empresa portuguesa Petrogal (ANP, 2017). Extrai-se também gás do campo de Mexilhão. Todo transporte é feito por dutos até a UTGCA, que redistribui o produto para o planalto através do Gasoduto Caraguatatuba-Taubaté (Gastau), e daí em diante para todo o sudeste, já integrado à malha de dutos do sudeste brasileiro.

Outra indústria que se destaca é a do turismo marítimo. Utilizando a base de dados do CGIg (Coordenação Geral de Imigração) - com as resoluções normativas do CNIg (Conselho Nacional de Imigração) - sobre registros de autorizações de trabalho estrangeiro no Brasil, filtrado para a nacionalidade filipina no estado de São Paulo (nacionalidade que predominou nos registros do SINCRE-PF em São Sebastião), vemos que esses imigrantes estão, em sua maioria, em profissões bastante características dessa indústria: são garçons, barmans, camareiros, cozinheiros e faxineiros. Vale lembrar que a base do CGIg contém os registros de autorizações de trabalho, que não

\footnotetext{
${ }^{4}$ Resolução Normativa nº72. Acessada através do link: http://acesso.mte.gov.br/legislacao/2006-11.htm
} 
necessariamente representam um indivíduo (já que a mesma pessoa pode receber mais de uma autorização de trabalho num mesmo ano calendário). No entanto, se pelo CGIg esses imigrantes estão registrados a partir do Código Brasileiro de Ocupações (CBO) e a profissão exercida por ele será - teoricamente - exatamente a mesma que a registrada, no SINCRE-PF eles estão registrados como "Oficial”, sem maiores especificidades. É possível que a base de dados do SINCRE-PF cause alguma confusão na análise das características ocupacionais e amparos jurídicos dos estrangeiros registrados no Brasil, o que evidentemente é o caso dos filipinos em trabalhadores marítimos; de acordo com Clemente (2014), a partir de observações etnográficas, é observável uma espécie de hierarquia entre as nacionalidades nas ocupações em plataformas, nas quais os trabalhadores filipinos (e outros asiáticos) são operários, enquanto noruegueses, ingleses e americanos estão em cargos de chefia. Isso parece estar em consonância com o que escreveu Zanin (2007) sobre o mercado de trabalhadores marítimos e a presença massiva e histórica de trabalhadores asiáticos na indústria de petróleo e gás. Não parece coerente esperar uma hierarquização diferente na indústria de turismo, e a base do CGIg indica que, de fato, pode ser que isso se reproduza.

A base do CGIg, no entanto, não possui informações por município (apenas por UF), o que impossibilita uma compreensão detalhada desses imigrantes que, ainda por cima, são temporários, já que estão incluídos na lógica e nos mercados transnacionais relativos às indústrias aqui discutidas. Os filipinos possuem, ainda, a especificidade de serem agenciados por empresas ainda em seu país de origem, cujo Estado opera na articulação e operacionalização do agenciamento desses trabalhadores que enfrentam a face mais organizada e acachapante da flexibilização do trabalho no século XXI. ${ }^{5}$

\section{Considerações Finais}

Todas essas transformações conferem à região um dinamismo que não era presente no século XX. Nesse novo cenário de investimentos públicos e privados, transnacionais, diretos e indiretos nas atividades de extração, transporte e tratamento do petróleo e seus derivados, além da presença do turismo internacional que retorna ao Porto de São Sebastião, vemos, em atividades básicas de estiva e arrumação no Porto de São Sebastião, a presença de trabalhadores brasileiros com sindicatos situados próximos à entrada do porto $^{6}$, e ao mesmo tempo a presença do trabalhador imigrante internacional.

\footnotetext{
${ }^{5}$ Essa discussão, com foco especificamente sobre os imigrantes filipinos em trabalhos marítimos, com análise e comparação dos dados presentes nas bases do SINCRE-PF e do CNIg, além de breve discussão sobre o papel do Estado filipino no agenciamento dessa força de trabalho está num texto, de nossa autoria, de 2017 (ainda não publicado).

${ }^{6}$ Isso foi observado em breve visita a campo no segundo semestre de 2016.
} 
No que tange às cidades da região e sua participação nesses processos, é importante destacar como a "antiga vocação" para o turismo não desapareceu. Seja nos nomes (Caraguatatuba ainda é chamada de Estância Balneária de Caraguatatuba) ou na continuação do turismo sazonal que caracterizou a região desde a década de 1960, essa "vocação" (Harvey, 2013) local divide espaço com essa nova "vocação" global e mesmo com o retorno da região para a rota do turismo marítimo.

O espaço do Litoral Norte paulista, suas migrações interna e internacional, seus movimentos de pendularidade intraregional e com o planalto (Região Metropolitana do Vale do Paraíba e Litoral Norte), deve ser compreendido tanto no âmbito local - suas raízes históricas - quanto no contexto local-global com a nova posição de Caraguatatuba e São Sebastião e suas articulações global-local que conferem à cidade novo dinamismo, novas potencialidades e novos desafios na aurora do século XXI.

\section{Referências Bibliográficas}

- ALVES, P.V.M. Imigração na modernização dependente: "braços civilizatórios" e atual configuração polarizada. Campinas, 2015. Tese de Doutorado, Unicamp, 2015.

- CARMO, R. L.Dinâmica demográfica, economia e ambiente na zona costeira de São Paulo. RobertoLuiz do Carmo; César Marques e Zoraide Amarante Itapura de Miranda. Em: Textos Nepo 63.Campinas: Núcleo de Estudos de População, Unicamp, 2012

- CLEMENTE, C.C. Faces do pré-sal brasileiro: migração, trabalho e sociabilidade. Revista Idéias nº9 (nova série). Campinas, 2014.

- COSTA, N.B.N. Migrações Internacionais e Refúgio no Brasil entre 2000 e 2014: uma análise espaço-temporal. Brasília, 2016. 125p. Dissertação de Mestrado. Departamento de Geografia. Universidade de Brasília (UnB).

- DAPP. Análise e avaliação do desenvolvimento institucional da política de imigração no Brasil para o século XXI. FGV, Rio de Janeiro, 2015.

- GONÇALVES, M.F. As engrenagens da locomotiva: Ensaio sobre a formação urbana paulista.Tese de Doutorado. Instituto de Economia/Unicamp. Campinas. 1998. 339p. 
- HARVEY. D. A Condição Pós-Moderna. 9a edição. Edições Loyola. São Paulo. 2003.

- LUCHIARI, M.T.D.P. Caiçaras, Migrantes e Turistas: a trajetória da apropriação da natureza no Litoral Norte paulista (São Sebastião - Distrito de Maresias). Campinas, 1992. 214p. Dissertação de Mestrado, Unicamp, 1992.

- MONIÉ, F. e VIDAL, S.M.S.C. Cidades, portos e cidades portuárias na era da integração produtiva. Rio de Janeiro, 2006.

-SASSEN, S. As Cidades na Economia Mundial. Studio Nobel. São Paulo. 1998. 